\title{
Computed tomography window affects kidney stones measurements
}

Alexandre Danilovic ${ }^{1}$, Bruno Aragão Rocha ${ }^{2}$, Giovanni Scala Marchini ${ }^{1}$, Olivier $\operatorname{Traxer}^{3}$, Carlos Batagello ${ }^{1}$, Fabio Carvalho Vicentini ${ }^{1}$, Fábio César Miranda Torricelli ${ }^{1}$, Miguel Srougi ${ }^{1}$, William Carlos Nahas ${ }^{1}$, Eduardo Mazzucchi ${ }^{1}$

${ }^{1}$ Departamento de Urologia do Hospital das Clinicas da Faculdade de Medicina da Universidade de São Paulo, SP, Brasil; ${ }^{2}$ Departamento de Radiologia do Hospital das Clínicas da Faculdade de Medicina da Universidade de São Paulo, SP, Brasil; ${ }^{3}$ Sorbonne Université, GRC n 20 Lithiase Renale, AP-HP, Hôpital Tenon, F-75020 Paris, France. University, Paris, France

\section{ABSTRACT}

Objectives: Measurements of stone features may vary according to the non-contrast computed tomography (NCCT) technique. Using magnified bone window is the most accurate method to measure urinary stones. Possible differences between stone measurements in different NCCT windows have not been evaluated in stones located in the kidney. The aim of this study is to compare measurements of kidney stone features between NCCT bone and soft tissue windows in patients submitted to retrograde intrarenal surgery (RIRS).

Materials and Methods: Preoperative and 90th postoperative day NCCT were performed in 92 consecutive symptomatic adult patients (115 renal units) with kidney stones between $5 \mathrm{~mm}$ to $20 \mathrm{~mm}(<15 \mathrm{~mm}$ in the lower calyx) treated by RIRS. NCCT were evaluated in the magnified bone window and soft tissue window in three axes in a different time by a single radiologist blinded for the measurements of the NCCT other method. Results: Stone largest size $(7.92 \pm 3.81$ vs. $9.13 \pm 4.08 ; \mathrm{mm})$, volume $(435.5 \pm 472.7$ vs. $683.1 \pm 665.0 ; \mathrm{mm} 3)$ and density $(989.4 \pm 330.2$ vs. $893.0 \pm 324.6$; HU) differed between bone and soft-tissue windows, respectively $(p<0.0001) 5.2 \%$ of the renal units $(6 / 115)$ were reclassified from residual fragments $>2 \mathrm{~mm}$ on soft tissue window to $0-2 \mathrm{~mm}$ on bone window.

Conclusion: Kidney stone measurements vary according to NCCT window. Measurements in soft tissue window NCCT of stone diameter and volume are larger and stone density is lesser than in bone window. These differences may have impact on clinical decisions.

\section{ARTICLE INFO}

Alexandre Danilovic

http://orcid.org/0000-0002-6963-6117

\section{Keywords:}

Kidney Calculi; Nephrolithiasis;

Patient Outcome Assessment

Int Braz J Urol. 2019; 45: 948-55

Submitted for publication:

November 28, 2018

Accepted after revision:

March 17, 2019

Published as Ahead of Print:

June 20, 2019

\section{INTRODUCTION}

Non-contrast computed tomography (NCCT) has become the gold standard for diagnosing urinary stones (1). NCCT is able to provide stone features as size, volume and density that are relevant for making clinical decisions. Stone size is of paramount importance for spontaneous stone passage (2). Stone volume is the best predictor of operative time and is an independent predictor of stone-free status in retrograde intrarenal surgery (RIRS) for kidney stones $(3,4)$. Hounsfield units (HU) density is able to differentiate uric acid sto- 
nes, to predict success of shockwave lithotripsy and to impact on operative time of RIRS using holmium laser lithotripsy (5-9). However, the measurements of these stone features may vary according to the NCCT technique (10).

Most data previously reported about urinary stones features were measured in soft tissue window conventional-dose NCCT (3-9). However, it has been demonstrated in distal ureteral stones that magnified soft tissue window NCCT is a poor predictor of the largest stone dimension (11) and that magnified bone window is the most accurate method to measure urinary stones in vitro and in vivo (12). The possible differences between windows of NCCT have not been evaluated in stones located in the kidney. The aim of this study is to compare kidney stone features between bone and soft tissue windows using the currently best practice protocol NCCT in patients submitted to RIRS.

\section{MATERIALS AND METHODS}

From August 2016 to August 2017, preoperative and 90th postoperative day (POD) NCCT were performed in consecutive symptomatic adult patients with kidney stones that chose to be treated by RIRS.

RIRS was offered as an option for the treatment of symptomatic kidney stones between $5 \mathrm{~mm}$ to $20 \mathrm{~mm}$. We limited the option of RIRS in the lower calyx for stones up to $15 \mathrm{~mm}$ in an attempt to maximize stone free rate and to reduce flexible ureteroscope damage (13-15). Lower calyx stones larger than $15 \mathrm{~mm}$ were treated by percutaneous nephrolithotomy (16).

Patients with kidney malformations, ureteral stenosis, previous ipsilateral endoscopic or open kidney surgery, hydronephrosis, indwelling double $\mathrm{J}$ stent and contraindications for RIRS were excluded.

NCCT was performed using a 64-slice GE Lightspeed CT Scanner ${ }^{\circledR}$ (General Eletric ${ }^{\circledR}$, USA) with a slice thickness of $1 \mathrm{~mm}$ and radiation low-dose protocol (low tube charge current-60mAs) in patients with Body Mass Index-BMI $<30 \mathrm{Kg} / \mathrm{m}^{2}$ and conventional protocol (160mAs) in patients with $>30 \mathrm{Kg} / \mathrm{m}^{2}$. Low-dose NCCT is recommended for the evaluation of urinary stones in non-obese patients due to equivalent detection of urolithiasis and stone measurements comparing to conventional dose NCCT using less ionized radiation $(17,18)$.

Magnified (400\%) NCCT were evaluated first in bone window (width, 1600HU/level, $500 \mathrm{HU}$ ) in axial, coronal and sagittal plane and then NCCT were evaluated in soft tissue window (width, 400HU/level, 40HU) by the same radiologist blinded for the results of the measurements of the bone window NCCT (Figure-1). Postoperative NCCT stone measurements were performed in the same fashion (Figure-2).

Stone density was measured by free hand ROI determination coincident with the stone borders. Stone volume was calculated as length $\mathrm{x}$ width $\times$ depth $\times \pi \times 0.167(1,19)$. Residual fragments were categorized as 0 when no residual fragments exists, $0-2 \mathrm{~mm}$ and $>2 \mathrm{~mm}$.

\section{STATISTICAL ANALYSIS}

Bone and soft tissue window NCCT results were compared using paired T-test, Wilcoxon Signed Rank. Bone and soft tissue window NCCT residual fragments were compared using McNemar-Bowker test of symmetry. Sample size was calculated based on the percentage of renal units with residual fragments more than $2 \mathrm{~mm}$ by NCCT of 38\% (20). Therefore, the sample size for a bicaudal test with significance level of 5\% and test power of 95\% is 115 renal units.

SAS 9.0 program ${ }^{\circledR}$ (SAS Institute Inc., Cary, NC, USA) was used with a significance level of 5\%.

\section{RESULTS}

Ninety-two patients were successfully submitted to RIRS. Bilateral procedures were performed in 23 patients $(25 \%)$ resulting in 115 renal units operated. Body Mass Index was $28.1 \pm 4.8, \quad 19.0-45.5 \mathrm{Kg} / \mathrm{m}^{2}$ (mean $\pm \mathrm{SD}$, range). Twenty-eight patients (35 renal units, 30.4\%) were obese (BMI $>30 \mathrm{Kg} / \mathrm{m}^{2}$ ) and were submitted to conventional-dose NCCT. Stone features evaluated by bone and soft tissue windows are compared in Table-1. Stone largest size, volu- 
Figure 1 - Preoperative magnified (400\%) NCCT bone window (ww 1600HU/wl 500HU) vs. soft tissue window (ww 400HU/ wl 40HU). A) bone window axial stone diameter, B) bone window coronal stone diameter, C) bone window sagittal stone diameter, D) bone window stone density, E) soft tissue window axial stone diameter, F) soft tissue window coronal stone diameter, G) soft tissue window sagittal diameter, H) soft tissue window stone density.

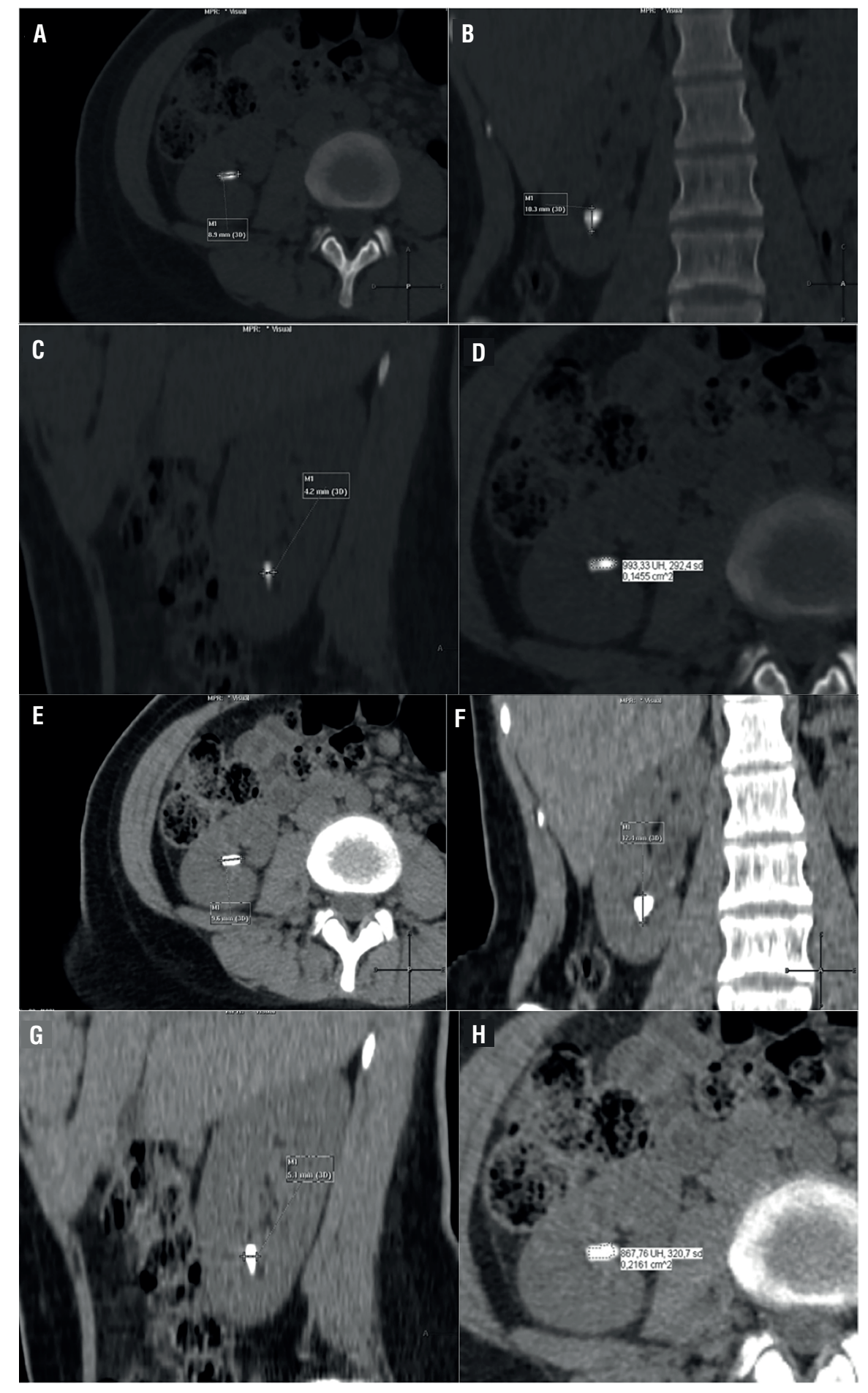


Figure 2 - Postoperative magnified (400\%) NCCT bone window (ww 1600HU/wl 500HU) vs. soft tissue window (ww 400HU/ wl $40 \mathrm{HU}$ ). A) bone window axial stone diameter, B) bone window coronal stone diameter, C) bone window sagittal stone diameter, D) soft tissue window axial stone diameter, E) soft tissue window coronal stone diameter, F) soft tissue window sagittal diameter.

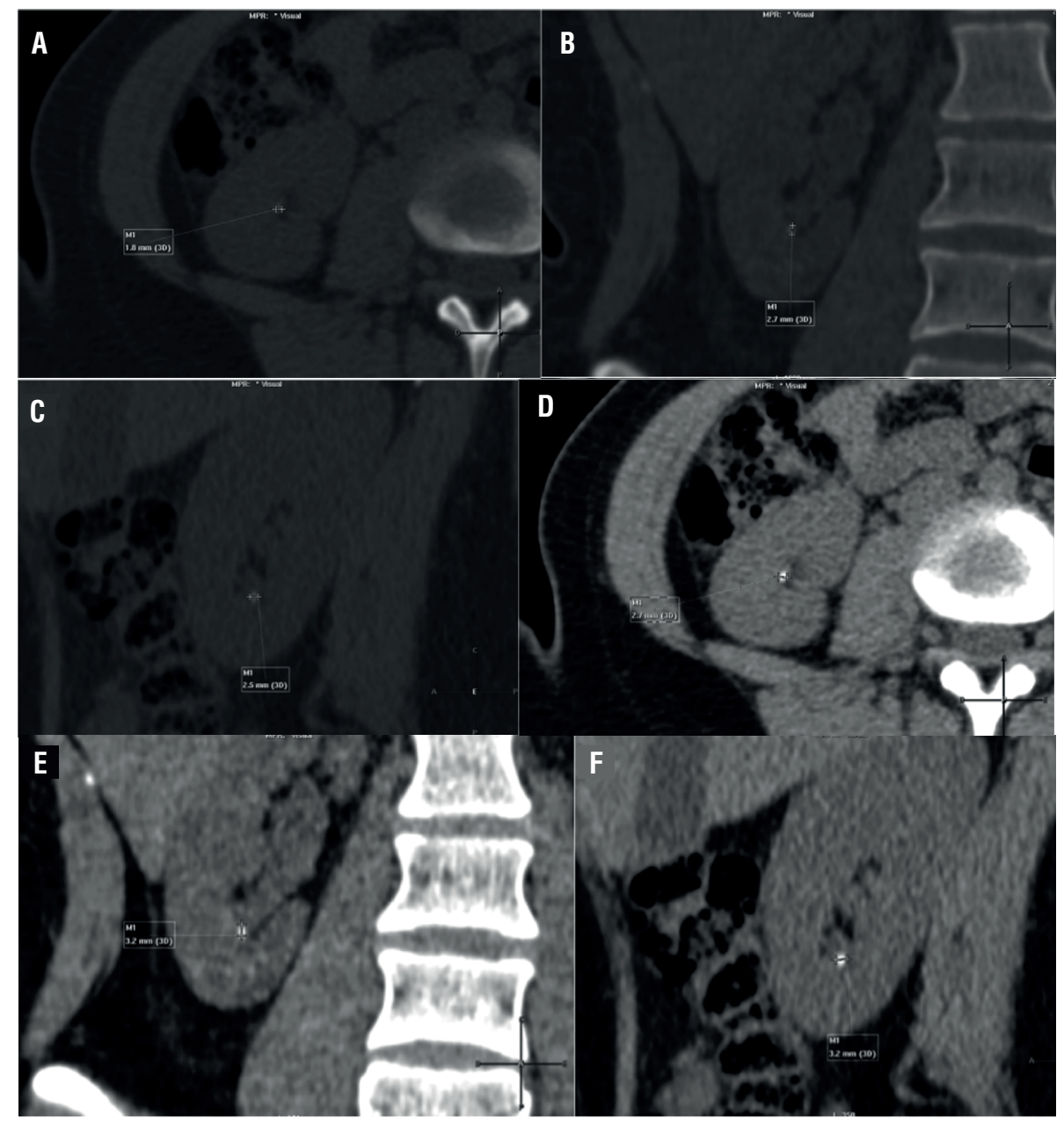

Table 1 - Comparison between pre-operative NCCT bone and soft tissue windows of the stone features of the115 renal units submitted to RIRS.

\begin{tabular}{lccc}
\hline Stone features & Bone window & Soft Tissue window & $p$-value \\
\hline Multiple stones $(\%)$ & $69(60.0)$ & $69(60.0)$ & 1.000 \\
Stone size $($ mean $\pm \mathrm{SD}, \mathrm{mm})$ & $7.92 \pm 3.81$ & $9.13 \pm 4.08$ & $<0.0001$ \\
Stone volume $\left(\right.$ mean $\left._{ \pm} \mathrm{SD}, \mathrm{mm}^{3}\right)$ & $435.5 \pm 472.7$ & $683.1 \pm 665.0$ & $<0.0001$ \\
Stone density $\left(\right.$ mean $\left._{ \pm} \mathrm{SD}, \mathrm{HU}\right)$ & $989.4 \pm 330.2$ & $893.0 \pm 324.6$ & $<0.0001$ \\
\hline
\end{tabular}


me and density differed between the two methods ( $\mathrm{p}<0.0001)$. Although residual fragments diameter was not significantly different when evaluated by NCCT using bone or soft tissue window ( $p=0.1116$ ) (Table-2), $5.2 \%$ of the renal units (6/115) were reclassified from residual fragments $>2 \mathrm{~mm}$ to $0-2 \mathrm{~mm}$.

The 90th postoperative day bone and soft tissue window NCCT revealed one asymptomatic small subcapsular hematoma in a stone free renal unit and two asymptomatic hydronephrosis, one in a stone free renal unit and other in a renal unit with $>2 \mathrm{~mm}$ residual fragment.

\section{DISCUSSION}

Low dose NCCT is the current gold standard for the evaluation of urinary stone disease due to its lower radiation exposure (0.7-2.8mSv) than conventional dose NCCT $(8-16 \mathrm{mSv})$ and high pooled sensitivity of 0.966 (95\% CI, 0.950-0.978) and a pooled specificity of 0.949 (95\% CI, 0.920-0.970), which are equivalent to conventional dose NCCT sensitivity of $97 \%$ and specificity of 96\% (17, 18). Besides, other authors found no significant difference in the measurement of stone size and HU between low dose and conventional NCCT $(17,21)$. However, conventional dose NCCT is still recommended for the evaluation of urinary stones in obese patient (BMI $\left.>30 \mathrm{Kg} / \mathrm{m}^{2}\right)$ (1).

We used low-dose NCCT with $60 \mathrm{mAs}$ in non-obese patients (BMI $<30 \mathrm{~kg} / \mathrm{m}^{2}$ ) and NCCT with $160 \mathrm{mAs}$ in obese patients for this study to minimize the radiation exposure without compromising image quality $(22,23)$. NCCT image noise varies proportional to the value of the square root of the miliampere product. Higher noise from ultra low-dose NCCT (24) may decrease accuracy in detecting small residual fragments $(<3 \mathrm{~mm})(25)$.

Other authors stressed the importance of standardization of making measurements on NCCT images (10). They demonstrated a larger variability for inter-reader $( \pm 1.3 \mathrm{~mm})$ than intra-reader (26). Narayan et al. demonstrated that stone density measurements vary depending on window, plane and ROI technique. They recommend that clinicians select a single ROI measurement technique and remain consistent to minimize variability (27). However, ROI measurement should include the periphery of the stone as we did by free hand technique to better represent the entire nature of that stone. As a result, we may better predict laser and operative time or even which laser technique (dusting, fragmentation or popcorn) is better according to stone density. A single senior radiologist evaluated all NCCT studies, in a different time, blinded for the results of the bone window NCCT stone measurements. This might have reduced the possible measurement bias.

Magnified bone window NCCT should be preferred for urinary stone evaluation due to better image quality for dense objects as it minimizes noise artifacts close to the stone limits $(12,25)$. In vitro study already demonstrated that soft tissue window overestimates stone size and bone window provides best accuracy (26). Clinically, it was shown that bone window allows a visual distinction between a stent and a stone $(28,29)$. On the other hand, urologists are more familiar with soft tissue window when looking at NCCT and most data related to stone features and NCCT were produced using soft tissue window.

In order to establish if there is a difference between kidney stone measurements in

Table 2 - Comparison between post-operative NCCT bone and soft tissue windows of the residual stone size of the115 renal units.

\begin{tabular}{lccc}
\hline Residual stone size & Bone window & Soft Tissue window & p-value \\
\hline $0 \mathrm{~mm}, \mathrm{~N}(\%)$ & $86 / 115(74.8)$ & $86 / 115(74.8)$ & 0.1116 \\
$0-2 \mathrm{~mm}, \mathrm{~N}(\%)$ & $10 / 115(8.7)$ & $4 / 115(3.5)$ & $25 / 115(21.7)$ \\
$>2 \mathrm{~mm}, \mathrm{~N}(\%)$ & $19 / 115(16.5)$ & & \\
\hline
\end{tabular}


bone and soft tissue windows, we compared preoperative urinary stone features and 90 POD results in both windows. We demonstrated that preoperative bone window NCCT image produce smaller size and volume stone and bigger density stone than soft tissue window ( $p<0.0001)$. These results have major clinical impact because regarding stone treatment, every millimeter counts for the decision to actively treat or not. Besides, stone-free rates of all modalities of active treatment of renal calculi are based on size, burden or volume of stone. We found differences in stone density probably because of variation in positioning their regions-of-interest due to different time of measurement as stressed by Williams Jr. (30) and to less noise in the stone surround.

Although we found no significant differences between both windows in the stone free status and complications in the follow-up evaluation, it is important to notice that in 5.2\% of the renal units operated the difference in size of residual fragments was clinically relevant. According to previous studies, residual fragments $>2 \mathrm{~mm}$ are more likely to experience growth and cause disturbance to patients (16, 31-33). Therefore, the correct measurement of residual fragment is of upmost importance to plain reintervention.

Our study has several strengths. It is a prospective study using preoperative and postoperative current best practice NCCT after RIRS in patients without kidney malformations, ureteral stenosis, previous ipsilateral endoscopic or open kidney surgery, hydronephrosis or indwelling double $\mathrm{J}$ stent, providing more accurate results. To the best of our knowledge, it is the first study to prospectively address a comparison between NCCT bone and soft tissue windows for kidney stones.

This study has some limitations. We did not compare the real size of the intact stone to the NCCT measured size because the stones were broken during RIRS. However, other authors already proved that bone window is more accurate comparing to real distal ureteral stones (11). Also, we used two different NCCT protocols. We used low-dose NCCT in non-obese patients and conventional dose NCCT in obese patients in order to minimize the radiation exposure. Previous authors showed that low-dose NCCT did not compromise image quality $(22,23)$. However, we did not examine these subgroups separately. Another limitation is the single center nature of our study. Therefore, our results should be validated by other high volume centers.

\section{CONCLUSIONS}

Kidney stone measurements vary according to NCCT window. Measurements in soft tissue window NCCT of stone diameter and volume are larger and stone density is lesser than in bone window. These differences may have impact on clinical decisions.

\section{ACKNOWLEDGEMENTS}

Financial support of Fapesp No. 2014/05130-2

\section{CONFLICT OF INTEREST}

None declared.

\section{REFERENCES}

1. Türk C, Knoll T, Petrik A, Sarica K, Skolarikos A, Straub M, et al. Guidelines on Urolithiasis. Arnhem, The Netherlands: EAU Guidelines Office; 2013.

2. Miller OF, Kane CJ. Time to stone passage for observed ureteral calculi: a guide for patient education. J Urol. 1999;162(3 Pt 1):688-90.

3. Sorokin I, Cardona-Grau DK, Rehfuss A, Birney A, Stavrakis $C$, Leinwand $G$, et al. Stone volume is best predictor of operative time required in retrograde intrarenal surgery for renal calculi: implications for surgical planning and quality improvement. Urolithiasis. 2016;44:545-50.

4. Ito H, Sakamaki K, Kawahara T, Terao H, Yasuda K, Kuroda $S$, et al. Development and internal validation of a nomogram for predicting stone-free status after flexible ureteroscopy for renal stones. BJU Int. 2015;115:446-51.

5. Saw KC, McAteer JA, Monga AG, Chua GT, Lingeman JE, Williams JC Jr. Helical CT of urinary calculi: effect of stone composition, stone size, and scan collimation. AJR Am J Roentgenol. 2000;175:329-32. 
6. Nakada SY, Hoff DG, Attai S, Heisey D, Blankenbaker D, Pozniak M. Determination of stone composition by noncontrast spiral computed tomography in he clinical setting. Urology. 2000;55:816-9.

7. Spettel S, Shah P, Sekhar K, Herr A, White MD. Using Hounsfield unit measurement and urine parameters to predict uric acid stones. Urology. 2013;82:22-6.

8. Shah K, Kurien A, Mishra S, Ganpule A, Muthu V, Sabnis RB, et al. Predicting effectiveness of extracorporeal shockwave lithotripsy by stone attenuation value. Endourol. 2010;24:1169-73.

9. Ito $\mathrm{H}$, Kawahara T, Terao H, Ogawa T, Yao M, Kubota $\mathrm{Y}$, et al. The most reliable preoperative assessment of renal stone burden as a predictor of stone-free status after flexible ureteroscopy with holmium laser lithotripsy: a single-center experience. Urology. 2012;80:524-8.

10. Lidén $M$, Andersson $T$, Geijer $H$. Making renal stones change size-impact of CT image post processing and reader variability. Eur Radiol. 2011;21:2218-25.

11. Kishore TA, Pedro RN, Hinck B, Monga M. Estimation of size of distal ureteral stones: noncontrast CT scan versus actual size. Urology. 2008;72:761-4.

12. Eisner BH, Kambadakone A, Monga M, Anderson JK, Thoreson $A A$, Lee $H$, et al. Computerized tomography magnified bone windows are superior to standard soft tissue windows for accurate measurement of stone size: an in vitro and clinical study. J Urol. 2009;181:1710-5.

13. Danilovic A, Cavalanti A, Rocha BA, Traxer 0, Torricelli FCM, Marchini GS, et al. Assessment of Residual Stone Fragments After Retrograde Intrarenal Surgery. J Endourol. 2018;32:1108-13.

14. Goldberg H, Golomb D, Shtabholtz Y, Tapiero S, Creiderman G, Shariv A, et al. The "old" $15 \mathrm{~mm}$ renal stone size limit for RIRS remains a clinically significant threshold size. World J Urol. 2017;35:1947-54.

15. Ozimek T, Cordes J, Wiessmeyer JR, Schneider MH, Hupe MC, Gilbert N, et al. Steep Infundibulopelvic Angle as a New Risk Factor for Flexible Ureteroscope Damage and Complicated Postoperative Course. J Endourol. 2018;32:597-602.

16. Türk C, Petřík A, Sarica K, Seitz C, Skolarikos A, Straub $M$, et al. EAU Guidelines on Interventional Treatment for Urolithiasis. Eur Urol. 2016;69:475-82.

17. Sohn W, Clayman RV, Lee JY, Cohen A, Mucksavage P. Low-dose and standard computed tomography scans yield equivalent stone measurements. Urology. 2013;81:231-4.
18. Niemann T, Kollmann T, Bongartz G. Diagnostic performance of low-dose CT for the detection of urolithiasis: a metaanalysis. AJR Am J Roentgenol. 2008;191:396-401.

19. Finch $W$, Johnston $R$, Shaida N, Winterbottom A, Wiseman 0. Measuring stone volume - three-dimensional software reconstruction or an ellipsoid algebra formula? BJU Int. 2014;113:610-4.

20. Rippel CA, Nikkel L, Lin YK, Danawala Z, Olorunnisomo V, Youssef RF, et al. Residual fragments following ureteroscopic lithotripsy: incidence and predictors on postoperative computerized tomography. J Urol. 2012;188:2246-51.

21. Alsyouf M, Smith DL, Olgin G, Heldt JP, Lightfoot M, Li R, et al. Comparing stone attenuation in low- and conventionaldose noncontrast computed tomography. J Endourol. 2014;28:704-7.

22. Bhatt K, Monga M, Remer EM. Low-dose computed tomography in the evaluation of urolithiasis. $J$ Endourol. 2015;29:504-11.

23. Zilberman DE, Tsivian M, Lipkin ME, Ferrandino MN, Frush DP, Paulson EK, et al. Low dose computerized tomography for detection of urolithiasis-its effectiveness in the setting of the urology clinic. J Urol. 2011;185:910-4.

24. Jin DH, Lamberton GR, Broome DR, Saaty HP, Bhattacharya $\mathrm{S}$, Lindler TU, et al. Effect of reduced radiation CT protocols on the detection of renal calculi. Radiology. 2010;255:100-7.

25. Glazer DI, Maturen KE, Cohan RH, Davenport MS, Ellis JH, Knoepp US, et al. Assessment of $1 \mathrm{mSv}$ urinary tract stone CT with model-based iterative reconstruction. AJR Am J Roentgenol. 2014;203:1230-5.

26. Argüelles Salido E, Aguilar García J, Lozano-Blasco JM, Subirá Rios J, Beardo Villar P, Campoy-Martínez P, et al. Lithiasis size estimation variability depending on image technical methodology. Urolithiasis. 2013;41:517-22.

27. Narayan VM, Bozorgmehri S, Ellen JH, Canales MT, Canales BK, Bird VG. Evaluating Region of Interest Measurement Strategies to Characterize Upper Urinary Tract Stones on Computerized Tomography. J Urol. 2017;197(3 Pt 1):715-22.

28. Tanrikut C, Sahani D, Dretler SP. Distinguishing stent from stone: use of bone windows. Urology. 2004;63:823-6.

29. Yoshida S, Hayashi T, Morozumi M, Osada H, Honda N, Yamada T. Three-dimensional assessment of urinary stone on non-contrast helical computed tomography as the predictor of stonestreet formation after extracorporeal shock wave lithotripsy for stones smaller than $20 \mathrm{~mm}$. Int J Urol. 2007;14:665-7. 
30. Williams JC Jr. Viewing windows do not alter Hounsfield units in CT scans. Urol Res. 2005;33:481-2.

31. Chew BH, Brotherhood HL, Sur RL, Wang AQ, Knudsen BE, Yong C, et al. Natural History, Complications and Re-Intervention Rates of Asymptomatic Residual Stone Fragments after Ureteroscopy: a Report from the EDGE Research Consortium. J Urol. 2016;195(4 Pt 1):982-6.
32. Kang M, Son $\mathrm{H}$, Jeong $\mathrm{H}$, Cho MC, Cho SY. Clearance rates of residual stone fragments and dusts after endoscopic lithotripsy procedures using a holmium laser: 2-year follow-up results. World J Urol. 2016;34:1591-7.

33. Hein S, Miernik A, Wilhelm K, Adams F, Schlager D, Herrmann TR, et al. Clinical significance of residual fragments in 2015: impact, detection, and how to avoid them. World J Urol. 2016;34:771-8.

\section{Correspondence address:}

Alexandre Danilovic, MD

Av. Dr. Eneas de Carvalho Aguiar, n 255, $7^{\circ}$ andar,

Sala 7175

São Paulo, SP, 05403-000, Brasil

Telephone: +55 11 2661-8080

E-mail: alexandre.danilovic@hc.fm.usp.br 